\title{
PERCEPTORES DE SUBSIDIO PARA MAYORES DE 55 AÑOS: CARA Y CRUZ DE LOS TRABAJOS DE COLABORACIÓN SOCIAL ${ }^{1}$
}

\author{
Miriam Fernández Mingo \\ Contratada Predoctoral. Universidad Carlos III de Madrid. \\ Área de Derecho del Trabajo y de la Seguridad Social
}

DOI: $10.1387 /$ lan-harremanak.15431

\section{ABSTRACT}

El presente trabajo tiene como objeto analizar la incidencia de la crisis económica de estos últimos años en el recurso a otras figuras distintas del trabajador por cuenta ajena y, en consecuencia, excluidas de la protección del Derecho del Trabajo y de la Seguridad Social, en cuanto a que no cumplen con alguna de las notas de laboralidad del artículo 1.1 del ET. En este contexto, se estudia cómo están evolucionando los trabajos de colaboración social en busca de soluciones a la crisis del sistema, con un desmesurado crecimiento de las adscripciones, de modo mayoritario en los perceptores de subsidio para mayores de 55 años que han agotado la prestación por desempleo y que presentan especiales dificultades de inserción laboral. Se están construyendo figuras hibridas, desdibujando fronteras y están naciendo nuevos estatus sociales huyendo de la laboralidad.

Palabras clave: Inserción laboral, trabajos de colaboración social, subsidio para mayores de 55 años, crisis de mercado de trabajo.

\footnotetext{
${ }^{1}$ Este artículo se enmarca dentro del Proyecto MINECO DER 2012-33178, «Evaluación sustantiva de las reformas laborales: una nueva metodología interdisciplinar», bajo la dirección de D. Jesús R. Mercader Uguina.
} 
This paper aims to analyze the impact of the economic crisis of recent years in the use of figures others than the worker, therefore excluded from the protection of Labor Law and Social Security, as they do not meet any of the notes for working items under Article 1.1 of ET. In this context, we study the evolution of the social collaboration works in order to find the solutions for the crisis of the system, with excessive growth of secondments, majority in recipients of subsidy for people over 55 who have exhausted the provided unemployment payments and who have special difficulties in finding work. They are building hybrid figures and blurring boundaries, erecting new social status fleeing working patterns.

Key Words: Employment, social collaboration work, subsidy por over 55 years, crisis of job market. 


\section{Introducción}

El presente estudio pretende analizar la reformulación que la «invención» de la fórmula administrativa de la colaboración social es; también el impactante crecimiento que las adscripciones están teniendo en la representación social y en la regulación tanto del trabajo como del desempleo. Y más detalladamente, de las estrategias de instrumentalización de estas fórmulas jurídicas diseñadas por parte de las Administraciones Públicas (en adelante, AAPP), fundamentalmente a través de subvenciones autonómicas a las Corporaciones Locales (en adelante, CCLL), y el impacto de esta fórmula en el deterioro del empleo. Si a ello sumamos las nuevas condiciones del subsidio para mayores de 55 ańos a partir del RDLey 20/2012, de 26 de diciembre, de medidas de sostenibilidad financiera de las Comunidades Autónomas (en adelante, CCAA) y entidades locales y otras de carácter económico (antes mayores de 52 años), el resultado es un «cóctel» que demanda un especial seguimiento de este colectivo.

\section{Reformulación de los trabajos de colaboración social}

A pesar de contar con cuarenta y cinco ańos de vida, los trabajos de colaboración social en España eran hasta el año 2013 casi unos completos desconocidos, utilizados durante décadas por las AAPP de modo casi residual.

Se definen como aquellos celebrados entre las AAPP y los trabajadores desempleados perceptores de prestación o subsidio de desempleo, sin pérdida de dichas prestaciones, complementadas hasta alcanzar su base reguladora y asegurándose al menos la percepción del Salario Mínimo Interprofesional (en adelante, SMI), en la realización de trabajos de utilidad social y que redunden en beneficio de la comunidad, con una duración máxima que no exceda al período que le falte por percibir la citada prestación o subsidio, sin que suponga cambio en su residencia habitual y coincidente con sus aptitudes físicas y profesionales. Constituyen éstos los únicos derechos reconocidos, que en modo alguno pueden equiparse a los del trabajador en sentido estricto - cotizan exclusivamente por las contingencias profesionales de Accidentes de Trabajo y Enfermedades Profesionales (en adelante, AT y EP) en la parte de aportación de la Administra- 
ción — ni ser considerado como tal —a falta de la nota de voluntariedad y por la naturaleza no salarial de las retribuciones-. En este sentido, es sintomático que se considere no laboral algo que es denominado "trabajo», cuando lo que se está produciendo, desde esta perspectiva, es una huida del Derecho Laboral.

Desde 2013 estamos siendo testigos de un espectacular aumento de las adscripciones de colaboración social en España, de forma especial en las Islas Baleares y en la Comunidad de Madrid, donde el programa comenzó a subvencionarse para los ayuntamientos de la región, extendiéndose a la vista del Plan Anual de Política de Empleo (en adelante, PAPE) para el año 2014 y del PAPE 2015 a otras CCAA como Aragón, Comunidad Valenciana, Murcia, Asturias y Cantabria.

El recurso desmesurado a esta inveterada figura, que lejos de ser novedosa (Mercader, 2013) ya era recogida por la derogada Ley Básica de Empleo de 1980 y se mantiene vigente en el capítulo V del RD 1445/1982, de 25 de junio, con las modificaciones operadas por el RD 1809/1986, de 28 de junio, y en el apartado 3 del artículo 213 del Título III del TRLGSS, toma su fundamento en las políticas de activación comunitarias (Torrents, 2006), con amparo en la actual crisis del mercado de trabajo, afectando de forma alarmante a los mayores de 55 ańos, con especiales dificultades para regresar al mercado laboral del que han sido expulsados. Existe aquí, de entrada, una primera disfunción, por cuanto son los mayores de 45 ańos los considerados desempleados de larga duración. En cualquier caso, los mecanismos de inserción no están resultando eficientes a la vista de las estadísticas de desempleo.

Las severas limitaciones presupuestarias de las AAPP, especialmente del nivel local, la incidencia en este ámbito y la prohibición de reposición de trabajadores en base a los planes de ajuste municipales, que se solapa con la alternativa de la insuficiencia presupuestaria como causa de despido objetivo y consiguiente reducción de empleo público, han desembocado en la revalorización de estos trabajos. Revalorización que también encuentra su causa en la inobservancia de las notas propias de la laboralidad, como socorrida solución en momentos de crisis del mercado de trabajo.

El amparo legal de esta praxis se obtiene de la modificación del artículo 25.2 de la Ley 56/2003, de Empleo, al permitir éste a las CCAA diseñar sus propias políticas activas de empleo, recogiendo ya el PAPE 2013 una línea de ayudas al Programa de Colaboración Social para las CCLL.

Sin embargo, cabría cuestionar el recurso en tiempos de crisis, pues si bien a corto plazo pudiera constituir una medida de ahorro para las AAPP, que se benefician de la medida, la falta de cotizaciones por parte de las mismas puede suponer a medio plazo, no solo un agravio comparativo para los trabajadores desempleados participantes de los trabajos de colaboración social en relación a los 
trabajadores con contrato laboral que trabajan para la misma Administración, sino además una pérdida de ingresos para la TGSS y, a largo plazo, una pérdida de derechos para las generaciones futuras.

Por otra parte, es cuestionable en términos de proporcionalidad de la medida, por cuanto no existe limitación que impida que el número de desempleados participantes en trabajos de colaboración social pueda superar incluso el número de trabajadores que prestan sus servicios, circunstancia que especialmente podría darse en el nivel local.

Se ha puesto en tela de juicio finalmente el uso correcto de la medida en términos de igualdad - por episodios discriminatorios en el acceso al programa excluyendo a los candidatos con bases reguladoras más altas, la exclusión de partida a colectivos sin ninguna protección o por remuneraciones inferiores a los perceptores de determinados subsidios (incluido el subsidio para mayores de 55 años) tomando como referencia el SMI en lugar de la base reguladora-, e incluso se ha planteado que muchos despidos en la AAPP se hayan desencadenado por su causa, llegando a darse supuestos en los que el propio trabajador despedido ha sido llamado para realizar trabajos de colaboración social en idéntica ocupación y para la misma entidad, lo que llama a la reflexión.

Precisamente, un presumible uso ilícito de los trabajos de colaboración social por parte de las AAPP, desemboca en el giro jurisprudencial de las SSTS de 27-12-2013, recursos 217/2012, 2798/2012, 3214/2012, 22-01-2014, y de 22-01-2014, recurso 3090/2012, a partir del cual los contratos de colaboración social constituyen fraude de ley cuando se conciertan por las AAPP para cubrir sus actividades normales y permanentes, dando respuesta a las demandas interpuestas que reclamaban que las tareas desempeñadas en trabajos de colaboración social constituían relaciones laborales de pleno derecho.

No obstante lo anterior, el RDLey 17/2014, de 26 de diciembre, se intuye que con la intención de evitar más demandas y aun dejando patente en su exposición de motivos el «reconocimiento de la ilegalidad» de la medida (Morón, 2015), argumenta la necesidad de garantizar la prestación de servicios en tanto no se produzca la dotación y provisión de los respectivos puestos de trabajo en convocatoria de empleo público, eximiendo a los perceptores de prestaciones por desempleo que hubieran iniciado la realización de estos trabajos en las AAPP con anterioridad al 27-12-2013 hasta la extinción del derecho, independientemente del incumplimiento de su debido carácter temporal o de la pérdida de la finalidad en las labores que estuvieran realizando y de que ésta fueran o no de utilidad social, que constituyen los requisitos fijados por el Tribunal Supremo en su más reciente jurisprudencia.

Cabe pues preguntarse en qué medida los trabajos de colaboración social podrían generalizarse y prolongarse en el tiempo para el colectivo de perceptores 
de subsidio para mayores de 55 ańos, candidatos naturales como consecuencia de la publicación del RDLey, habida cuenta de que previsiblemente la duración del subsidio para mayores de 55 ańos sería mucho más amplia que para un desempleado perceptor de una prestación contributiva o de otro tipo de subsidio, de dos años y seis meses de duración máxima respectivamente y, en consecuencia, mayor sería el periodo de adscripción al programa, con el agravante de que podría llegar a alcanzar los trece ańos. Por tanto, teóricamente la modificación del RDLey 17/2014 no «incentiva» nuevas adscripciones, sino que trata de «legalizar» las existentes que no cumplan los citados requisitos.

Aunque los argumentos ofrecidos por el Ejecutivo son ampliamente criticados, no podría afirmarse taxativamente que la nueva norma desautorice la doctrina judicial, pues propone la aplicación ponderada de la sentencia de cara al futuro, limitada con carácter retroactivo y a determinados colectivos, lo que sí podría cuestionar su discrecionalidad y la constitucionalidad de esa decisión.

\section{El nuevo subsidio por desempleo para mayores de 55 años}

Partiendo de la consideración de los perceptores de subsidio para mayores de 55 ańos como principal colectivo destinatario de la excepción prevista en el RDLey 17/2014, procede ahondar en su naturaleza. Se trata así de una ayuda que recibirán las personas en cumplimiento del requisito de edad hasta la fecha en que se jubilen, siempre y cuando cumplan otros requerimientos económicos para esta modalidad de subsidio.

De forma resumida, los requisitos de acceso ${ }^{2}$ que debieran reunirse en el momento del hecho causante son: estar desempleado e inscrito como demandante de empleo, siendo condición sine qua non no haber rechazado oferta de empleo adecuada y suscribir compromiso de actividad, tener 55 o más años, haber cotizado por desempleo al menos seis años, reunir las condiciones del jubilado (salvo la edad legal) y carecer de rentas, cualquiera sea su naturaleza, superiores al $75 \%$ del SMI por unidad familiar, excluida la parte proporcional de dos pagas extraordinarias (486,45 euros/mes en 2015).

El compromiso de actividad y la búsqueda activa de empleo (en adelante, BAE) se podrían aglutinar en perseguir la ocupabilidad del trabajador desempleado (Blázquez y Quintero, 2002). La participación de un desempleado perceptor de subsidio para mayores de 55 años en trabajos de colaboración social podría fundamentarse en el cumplimiento del compromiso de actividad siempre que no se perdiera de vista la BAE.

2 Artículos 207 y 215 del TRLGSS, modificados por RDLey 17/2014. 
El RDLey 20/2012, de 13 de julio, de medidas para garantizar la estabilidad presupuestaria y el fomento de la competitividad introduce cambios en los subsidios por desempleo. En el caso que nos ocupa del subsidio por desempleo para las personas mayores aunque no tengan cargas familiares, extensible hasta la jubilación ${ }^{3}$ :

- Se produce un incremento de 52 a 55 años para percibir ese subsidio por desempleo:

Concretamente, modifica el apartado 3 del artículo 215 del TRLGSS, de modo que serán beneficiarios del subsidio por desempleo «los trabajadores mayores de cincuenta y cinco ańos, aun cuando no tengan responsabilidades familiares, siempre que se encuentren en alguno de los supuestos contemplados en los apartados anteriores, hayan cotizado por desempleo al menos durante seis años a lo largo de su vida laboral y acrediten que, en el momento de la solicitud, reúnen todos los requisitos, salvo la edad, para acceder a cualquier tipo de pensión contributiva de jubilación en el sistema de la Seguridad Social».

Añade como novedad que "para obtener el subsidio el trabajador deberá tener cumplida la edad de cincuenta y cinco años en la fecha del agotamiento de la prestación por desempleo o del subsidio por desempleo; o tener cumplida esa edad en el momento de reunir los requisitos para acceder a un subsidio de los supuestos contemplados en los apartados anteriores o cumplirla durante su percepción».

Por otra parte, conforme a la nueva redacción del apartado 3 del artículo 216 del TRLGSS, relativo a la duración del subsidio, para este supuesto previsto en el apartado 1.3 del artículo 215 de la misma, el subsidio se extenderá, como máximo, hasta que el trabajador alcance la edad que le permita acceder a la pensión contributiva de jubilación, en cualquiera de sus modalidades. Anteriormente, el trabajador tenía que alcanzar la edad ordinaria exigida en cada caso para causar derecho a la pensión contributiva de jubilación.

- Existe una mayor exigencia en la prueba de rentas para percibir el subsidio para los mayores, por cuanto aumenta del $50 \%$ al $100 \%$ el tipo de interés legal del dinero vigente aplicado para calcular la renta atribuida al valor de su patrimonio:

El subsidio pasa de ser por las rentas de las personas a ser por las rentas de la unidad familiar.

3 INFORME Y VALORACIÓN sobre el REAL DECRETO LEY 20/2012, de 13 de julio (BOE 14.7.2012), de medidas para garantizar la estabilidad presupuestaria y el fomento de la competitividad. Comisión Ejecutiva Confederal Confederación Sindical de Comisiones Obreras. 
Como consecuencia del endurecimiento de este requisito, si un desempleado participante en trabajos de colaboración social decidiera denunciar el supuesto de fraude de ley, en caso de obtener el reconocimiento de la relación laboral, se suspendería el subsidio que tuviera reconocido y tendría que generar uno nuevo conforme a las reformadas condiciones establecidas en el RDLey, de modo que en muchos casos la prueba de renta considerada por unidad familiar le impediría el reconocimiento del derecho, al dejar de alcanzar los requisitos que antes cumplía considerando la renta de las personas. Esta casuística podría provocar que los propios afectados optaran por no presentar demanda.

- La cotización en concepto de contingencias comunes de los beneficiarios de esta prestación se reduce desde el $125 \%$ al $100 \%$ de la base minima de cotización:

Según la DT 5.a «los trabajadores que, por aplicación del artículo 218 del texto refundido de la Ley General de la Seguridad Social, tuvieran fijada como base de cotización, durante la percepción del subsidio por desempleo, el 125 por cien del tope mínimo de cotización vigente en cada momento, pasaran a tener como base de cotización el 100 por cien de ese tope mínimo a partir del día primero del mes siguiente al de la entrada en vigor de este Real Decreto Ley».

- También se endurecen los criterios de finalización del subsidio de mayores de 52 años (ahora de 55 años)

De tal forma que la duración del mismo será hasta la fecha en la que el trabajador pueda jubilarse por cualquiera de las modalidades existentes. Hasta ahora, el trabajador elegía la mejor opción de jubilación y en tanto no optaba por jubilarse seguía cubierto por este subsidio; sin embargo, a partir de la entrada en vigor de este RDLey puede haber, bien periodos sin cobertura de desempleo, bien la obligación de acceder a una jubilación con coeficientes reductores.

En lo que se refiere a la cuantía del subsidio, regulado en el apartado 1 del artículo 217 TRLGSS, «la cuantía del subsidio por desempleo será igual al 80 por 100 del indicador público de rentas de efectos múltiples mensual vigente en cada momento». Añade en su nueva redacción para el caso de desempleo por pérdida de un trabajo a tiempo parcial que «dicha cuantía se percibirá en proporción a las horas previamente trabajadas en los supuestos previstos en los párrafos a) y b) del apartado 1.1, y en los apartados 1.2 y 1.3 del artículo 215». Para 2015 la ayuda es de 426 euros mensuales, por medio de la cual se sigue cotizando, también por jubilación, siendo el único subsidio de estas características en nuestro país.

Precisamente es en este punto en el que conviene detenerse a efectos del presente trabajo. Ya la Ley 27/2011, de 1 de agosto, sobre actualización, ade- 
cuación y modernización del sistema de Seguridad Social, integraba lagunas y recogía los casos en los que no queda desprotegido el trabajador (Aragón, 2013). Según el apartado 1 del artículo 218 de la TRLGSS relativo a cotización durante la percepción del subsidio, «durante la percepción del subsidio por desempleo para trabajadores mayores de cincuenta y cinco años la entidad gestora deberá cotizar por la contingencia de jubilación».

Partiendo de la consideración de las retribuciones percibidas por el desempleado participante en trabajos de colaboración social, se distingue entre la prestación o subsidio por desempleo - con cargo al Servicio Público de Empleo Estatal (en adelante, SEPE) —, y la diferencia entre las cantidades que perciban por dicha prestación o subsidio y el importe total de la base reguladora para el cálculo de la prestación contributiva que estuviese percibiendo o que hubiera agotado antes de percibir el subsidio, garantizándose, en todo caso, el cien por cien del SMI vigente en cada momento, que para 2015 está fijado en 648,60 euros brutos mensuales - con cargo a la AAPP-.

Si se tiene en consideración que por la parte de aportación de la AAPP a la que se adscribe no se producen cotizaciones más que en concepto de AT y EP, la cotización por la contingencia de jubilación por parte del SEPE garantizaría al perceptor del subsidio para mayores de 55 años, cuando participara en algún programa de colaboración hasta la extinción del derecho una vez alcanzada la edad de jubilación, el cumplimiento del requisito de haber cotizado durante los dos últimos años (carencia específica, inmediatamente anterior al hecho causante), siempre que además hubiera alcanzado el mínimo de quince ańos cotizados (carencia genérica o global).

Cuando dentro de esta carencia genérica existan periodos durante los cuales se haya percibido la prestación contributiva por desempleo, se computarían como periodo cotizado para la jubilación, colaborando a que se alcance dicho mínimo o a que aumente el porcentaje que se aplica a la base para la fijación de la cuantía si el mínimo ya se hubiere alcanzado.

Sin embargo, cabe matizar que durante la percepción del subsidio para mayores de 55 años, los periodos cotizados solo repercuten en lo relativo a su cuantía, no sumándose los años cotizados cuando no se hubieran alcanzado previamente los citados quince años cotizados que como mínimo se requieren para acceder a la pensión. Ha de tenerse en cuenta que las cotizaciones ingresadas por la entidad gestora durante la percepción del subsidio por desempleo para mayores de 55 años, de conformidad con la DA 28. ${ }^{a}$ LGSS, en la redacción dada por la Ley 50/1998, sólo tendrán efecto para el cálculo de la base reguladora de la pensión de jubilación y el porcentaje aplicable a aquélla; no teniendo en ningún caso validez y eficacia jurídica para acreditar el período mínimo de cotización exigido en el art. 161.1.b) de esta Ley, que de conformidad con su art. 215.1.3, ha debido quedar acreditado en el momento de la solicitud del subsidio. 


\section{Las dos caras de la moneda: bondades y peligros del programa de colaboración social y cómo afecta a los beneficiarios del subsidio para mayores de 55 años}

Se concluirá resumiendo la cara más gentil de los trabajos de colaboración social en contraposición a los efectos perversos de la medida, con especial alusión a cómo está afectando a los perceptores de subsidio para mayores de 55 ańos y su posible repercusión en las pensiones. El programa tiene sus detractores y quienes lo apoyan.

En términos generales, las bondades más plausibles de los trabajos de colaboración social tienen que ver con: las posibilidades de mejora de la empleabilidad y de la recualificación profesional de los colectivos especialmente afectados por el desempleo, entre los que se encontrarían los mayores de 55 años beneficiarios de subsidio; la contraprestación económica percibida por los participantes en el programa que complementa a la prestación o subsidio procedente del SEPE; y el nada desdeñable factor psicológico generado sobre aquel que se siente ocupado, útil e integrado en la sociedad, haciéndose efectivo el concepto de solidaridad colectiva por prestarse a realizar determinados trabajos en beneficio de la colectividad que lo auxilia, lo que enlaza además con las políticas de activación; y a priori, en su consideración de política de empleo, debería de mejorar su empleabilidad.

No obstante, la peculiar interpretación de este inciso legal abre la puerta a las disfunciones. Tan discutible es lo apuntado que antes se señalaban varias sentencias que sostienen el fraude de ley al quedar adscritos a trabajos de permanencia en actividades normales y permanentes de la AAPP, en referencia al giro jurisprudencial de las STS de 27/12/2013 y 22/01/2014 (asunto Canarias).

Es en este punto donde se tratará de explicar cómo los trabajos de colaboración social alcanzan de modo especial a los perceptores de subsidio para mayores de 55 años. Entre otras cuestiones, son objeto de estudio las siguientes:

1. En primer lugar, en respuesta a estas sentencias, la exposición de motivos del RDLey 17/2014 es muy significativa, por cuanto justifica en la necesidad de prestación de servicios por las AAPP y de modo transitorio hasta producirse su cobertura mediante convocatoria de empleo público, que quienes hubieran accedido al programa de colaboración social con anterioridad al 27 de diciembre de 2012, pueden mantener su adscripción mientras perdure el derecho a subsidio: hasta 13 años para los perceptores de subsidio para mayores de 55 años, que se presumen como el principal colectivo al que afecta la medida; de un lado mantiene ocupados a estos perceptores con especiales dificultades de reinserción laboral hasta alcanzar la edad de jubilación, pero provocando graves perjuicios en el nivel de protección, no solo en lo que afecte a los participantes en el pro- 
grama, que verán minorada la cuantía de su pensión al solo cotizar a través del SEPE, sino también en el sistema de pensiones en su conjunto, por no producirse las cotizaciones que verdaderamente corresponderían para el trabajo prestado durante un periodo de tiempo prolongado por parte de este nuevo estatus social cada vez más numeroso. Si en teoría la finalidad de la medida buscaba salvar el sistema público de pensiones, habría que valorar si en la práctica dejarían de ingresarse las cantidades que de otra manera se estarían produciendo cuando se tratara de verdaderas contrataciones laborales, contextualizado en un momento crítico.

Por otra parte, la percepción del subsidio (que no deja de ser un gasto para las arcas públicas) frente a la percepción del salario supone dejar de sumar para pasar a restar y en este sentido también podría afectar a la globalidad del sistema.

No obstante, aunque todo apunta a que en cierta medida afectaría al sistema de pensiones, probablemente mucho menos de lo que aparenta. Sin duda, el principal afectado sería el trabajador que está en adscripción en cuanto a que incidiría sobre su propia pensión y que, trabajando, no tiene reconocidas esas cotizaciones ni tendrá en el futuro prestaciones conforme al trabajo realmente realizado, creándose un problema en la calidad (cuantía) de las pensiones de las personas que hayan participado en trabajos de colaboración social, más cuando se hubiera producido de forma continuada en el tiempo. Su participación en los trabajos de colaboración social supondría un menor ingreso de cotizaciones que si tuviera un contrato laboral ordinario y al no haber cotizaciones por la contingencia de jubilación, tampoco existiría reconocimiento del derecho a esos efectos. En definitiva, el oportuno recurso a los trabajos de colaboración social parece configurarse como una medida de ahorro del Estado en perjuicio del trabajador, que es quien verdaderamente paga el desequilibrio del sistema.

2. En segundo término, previo a estas sentencias, ante una interpretación sui géneris del pionero programa de recualificación de trabajadores desempleados en trabajos de colaboración social en la Comunidad de Madrid, junto a los perceptores de la Renta Activa de Inserción (RAI), a los desempleados participantes en trabajos de colaboración social solo se les complementa hasta alcanzar el $\mathrm{SMI}^{4}$. Ello contrariamente a lo dispuesto en el artículo 38.4 del RD 1809/1986,

\footnotetext{
${ }^{4}$ PCOC-524/2014 RGEP.3915. Pregunta de respuesta oral en Comisión, a iniciativa de la Ilma. Sra. D. a Josefa Navarro Lanchas, diputada del Grupo Parlamentario Socialista en la Asamblea de Madrid, al Gobierno, sobre si se han dado instrucciones desde la DGE para que a los perceptores de los subsidios de mayores de 52/55 años que han agotado la prestación por desempleo, participantes en trabajos temporales de colaboración social de la Orden 2445/2013, el complemento de rentas a abonar se calcule hasta la cuantía del salario mínimo interprofesional en vez de la base reguladora de la prestación por desempleo de nivel contributivo. Comisión de Empleo, Turismo y Cultura de la C.M. 16 de abril de 2014 .
} 
de 28 de junio, que indicaba que como mínimo se garantizaría la percepción del SMI, no que tuviera que tomarse como referencia éste en sustitución de la base reguladora, incluso para los supuestos en los que la prestación o subsidio se hubiera agotado. A resultas de su tenor literal, «los trabajadores que participen en la realización de obras, trabajos o servicios a que se refiere el número uno de este artículo tendrán derecho a percibir con cargo al INEM la correspondiente prestación o subsidio por desempleo. Las Administraciones Públicas completarán, mientras realicen tales trabajos, la prestación o subsidio hasta el importe total de la base reguladora para el cálculo de la prestación contributiva que estuviere percibiendo o que hubiere agotado antes de percibir el subsidio. En todo caso, se garantizará el $100 \%$ del SMI vigente en cada momento». Esta ha sido una de las causas que ha influido en el incremento de demandas ante el Juzgado de lo Social.

En esta línea, puede considerarse la Comunidad de Madrid exponente de las cifras más elevadas en adscripciones a trabajos de colaboración social y «experiencia piloto» de la recuperación de una fórmula casi olvidada, ya que en 2013 promueve por primera vez el mencionado programa, pasando de 42 contratos de colaboración social en 2012, a 3.849 en 2013 , lo que supone un incremento porcentual desmesurado, del $9.064,29 \%$. Iniciativa adoptada posteriormente por otras CCAA in crescendo.

De ahí cabe afirmar que se están construyendo figuras híbridas, desdibujando fronteras y están naciendo nuevos estatus sociales huyendo de la laboralidad. Aunque parece alcanzarse la ocupabilidad del trabajador desempleado, lo haría en una contratación carente de algunas de las notas de laboralidad para dar una solución a las especiales dificultades de inserción para este colectivo.

3. De este modo, en un tercer inciso, el también citado RDLey $20 / 2012$ encierra en su finalidad un intento de reducir la litigiosidad, dado que al aumentarse la edad del subsidio para mayores de 52 años hasta los 55 y endurecerse los requisitos de renta, pasándose a considerar la unidad de familiar, los beneficiarios temerían perder sus condiciones actuales en caso de presentar demanda por fraude de ley cuando dejaran de cumplir los requisitos en una nueva solicitud; además de una tendencia de los beneficiarios del subsidio a perpetuar su situación, bien como desempleado, bien como participante en trabajos de colaboración social, llegando a renunciar a su inserción laboral efectiva con tal de no perder las condiciones en base a las que fue concedido dicho subsidio.

4. Por otra parte, la participación en trabajos de colaboración social tiene efectos directos en la protección social del participante en el programa a la luz de lo recogido en la LGSS. A saber, estos efectos serían los siguientes:

- A tenor del artículo 213.3, los trabajos de colaboración social cotizan solo por AT y EP (afecta a la parte de aportación de la AAPP a la que se 
adscriben estos trabajos), produciéndose un menor ingreso de cotizaciones que con un contrato ordinario, lo que afectaría al cálculo de la cuantía de las pensiones.

- A resultas del artículo 218.1, los perceptores del subsidio para mayores de 55 años cotizan de forma excepcional por la contingencia de jubilación (afecta a la parte de aportación del SEPE).

- De conformidad al precepto, la DA $28^{\mathrm{a}}$, en la redacción dada por la Ley 50/1998, señala que las cotizaciones ingresadas durante el periodo de percepción del subsidio para mayores de 55 años, solo tiene efectos en términos de cuantía y no sobre el periodo mínimo exigido para el acceso a las pensiones, de modo que quienes no tuvieran quince ańos de cotización previos no adquirirán el derecho a pensión de jubilación desde los trabajos de colaboración social al no haber cotizado los dos últimos años.

5. Sin embargo, y por último, también podría considerarse que tiene efectos indirectos en el sistema en su conjunto al reemplazarse empleo público, abaratándose en consecuencia la prestación de los servicios públicos y paralizando la creación de empleo. Tampoco se produciría el ingreso correspondiente a las cotizaciones por el trabajo prestado durante un periodo de tiempo prolongado, frente al gasto que supondría la percepción del subsidio, como veíamos anteriormente, y en este sentido, también podría afectar a la globalidad del sistema.

\section{Conclusiones}

Como resultado de la interpretación de este entramado normativo, parece, en definitiva, dibujarse un mapa de ruta perfectamente trazado [Anexo I], cuando se ponen en relación actuaciones aparentemente dispares. El RDLey 17/2014, de 26 de diciembre y el RDLey 20/2012, la promoción del programa de colaboración social desde las CCAA al amparo del artículo 26.2 de la Ley 56/2003, de 26 de noviembre, de Empleo, los planes de ajuste de los ayuntamientos por impedir éstos realizar contrataciones laborales y que invitan a adoptar medidas alternativas; sin olvidar la oportuna reducción que se viene produciendo en las tasas de desempleo habida cuenta de la consideración de «ocupado» del desempleado participante en trabajos de colaboración social. Actuaciones que, desde un modesto entender, no son sino piezas de un puzzle que pretende responder a una misma lógica, arropada por un nuevo discurso gubernamental en el que la desprotección se presenta como protección (Serrano, 2014), contraviniendo la doctrina del TS e incumpliendo abiertamente la propia normativa reguladora de los trabajos de colaboración social, especialmente en las notas de temporalidad y utilidad social, aun de forma transitoria. 
Habría pues que preguntarse si la evolución que se está produciendo en la figura de los trabajos de colaboración social va encaminada a la pretendida salvación del sistema o, por el contrario, el desmesurado aumento de las adscripciones en un número creciente de CCAA se está consolidando en un nuevo estatus social desprovisto de derechos laborales, perpetuando en éste hasta alcanzar la edad de jubilación a los mayores de 55 años que una vez fueron "trabajadores». Se confirmaría por tanto una pérdida de cantidad y calidad, tanto en el empleo como en las prestaciones.

Para concluir, la cuestionable reinserción y activación del sujeto, los episodios de discriminación producidos como consecuencia de la ambigüedad en los derechos y ante las carencias normativas, la desinformación de los destinatarios últimos de estos trabajos, la pérdida de la utilidad social que daba razón de ser al programa y de la cantidad y calidad de empleo "real», y sobre todo, el uso desmesurado y fraudulento acontecido, bien podría condicionar la viabilidad de los trabajos de colaboración social a una necesaria revisión normativa y de los mecanismos de control.

\section{Bibliografía}

Aragón, Jorge; Rochas, Fernando; Santana, Ana y Torrents, Jorge (2005): «El compromiso de activación y las políticas de empleo en España», Paper presentado en el Seminario Activation policies and labour market regimes, ETUI, Bruselas.

Aragón Gómez, Cristina (2013): «La prestación contributiva de Seguridad Social», Pamplona, Lex Nova, ISBN 978-84-9898-653-2.

Blázquez Agudo, Eva María y Quintero Lima, María Gema (2012): «La protección por desempleo: ¿la ocupabilidad como contrapartida?», Aranzadi Social: Revista Doctrinal, ISSN 1889-1209, Vol. 5, Núm. 7 (Nov), 2012, pp. 123-151.

Boltaina i Bosch (2005): «Empleo precario y conflictos jurídicos en las administraciones públicas, locales y autonómicas", Cuadernos constitucionales de la Cátedra Fadrique Furió Ceriol, ISSN 1133-7087, N. ${ }^{\circ}$ 52-53, Ejemplar sobre Nuevos retos para las administraciones locales y autonómicas en España, pp. 185-219.

Castińeira Fernández, Jaime (199): «Los trabajos de colaboración social», Trabajo subordinado y trabajo autónomo en la delimitación de fronteras de derecho del trabajo: estudios en homenaje al profesor José Cabrera Bazán, Tecnos, ISBN 84-309-3326-3, pp. 274-295.

Comisión Ejecutiva Confederal. Confederación Sindical de CC.OO. (2012): Informe y valoración sobre el Real Decreto Ley 20/2012, de 13 de julio (BOE 14.7.2012), medidas para garantizar la estabilidad presupuestaria y el fomento de la competitividad.

Confederación de Empresarios de Andalucía (2012): Informe sobre las principales novedades del Real Decreto-Ley 20/2012, de 13 de julio, de medidas para garantizar la estabilidad presupuestaria y de fomento de la competitividad, Andalucía, CEA. 
Confederación Sindical de CC.OO. (2013): «El sistema de protección social en España. Los efectos derivados de la crisis y las reformas», Cuadernos de Información Sindical en España. Depósito Legal: M-33437-2013, Madrid.

Federación de Servicios a la Ciudadanía de CC.OO. Centro de Estudios (2012): Modificaciones legislativas RDL 20/2012, www.fsc.ccoo.es.

Federación de Servicios a la Ciudadanía de CC.OO. (2014): Tablas de evolución de adscripciones de colaboración social. Fuente: Estadística de contratos: datos acumulados de Diciembre 2012 y Diciembre 2013. SEPE. MESS, Elaboración propia, 7 de marzo de 2014, www.fsc.ccoo.es.

Federación de Servicios de CC.OO. (2015): Ley 27 de 2011 de Reforma de las Pensiones. Resumen y dudas más frecuentes.

Fernández Rodríguez, Carlos J. y Serrano Pascual, Amparo (2014): El Paradigma de la flexiguridad en las politicas de empleo españolas: un análisis cualitativo, CIS.

Fundación Primero de Mayo (2014): "Los perfiles del paro", Colección Estudios, Núm. 80, ISSN: 1989-4732, febrero de 2014.

FundaCión 1. ${ }^{\circ}$ DE MAYO DE CC.OO. (2012): Las Reformas Laborales en España y su repercusión en materia de contratación y empleo: 52 reformas desde la aprobación del Estatuto de los Trabajadores en 1980, Informe de Febrero de 2012.

García-Perrote Escartín, Ignacio; Mercader Uguina, Jesús R. (2013): «El polémico retorno de los contratos temporales de colaboración social», Justicia Laboral: revista de Derecho del Trabajo y de la Seguridad Social, ISSN 1576-169X, Núm. 54, 2013, pp. 3-7.

GonzÁlez Ortega, Santiago (1983): «El trabajo temporal de colaboración social», Las Relaciones Laborales y la reorganización del sistema productivo, I Jornadas Universitarias Andaluzas de Derecho del Trabajo y Relaciones Laborales, ed., Monte de Piedad y Caja de Ahorros de Córdoba, Córdoba, pp. 131 y ss.

Lago Peñas, Manuel (2015): «Análisis gráfico de la pobreza y la desigualdad salarial», Cuadernos de Acción Sindical, Confederación Sindical de CC.OO., Marzo de 2015.

LÁzAro SÁNCHEZ, José Luis. (2012): «La utilización por las administraciones públicas de los trabajos temporales de colaboración social», Temas laborales: Revista andaluza de trabajo y bienestar social, ISSN 0213-0750, Núm. 113. 2012, pp. 217-228.

López López, Jesús (2002): «Utilización abusiva de trabajadores en régimen de colaboración social por las Administraciones Públicas», Información laboral. Legislación y convenios colectivos, ISSN 0214-6045, Núm. 21, 2002, pp. 5-12.

MESS. SEPE: Plan Anual de Política de Empleo 2015 (borrador), 6 de abril de 2015.

Morón Prieto, Ricardo (2015): «El Gobierno se salta la doctrina del Supremo y trata de frenar las demandas de parados voluntarios», disponible en http://www.eldiario.es/ economia/Gobierno-limitar-reclamaciones-parados-voluntarios_0_348915324.html

Ortega, María Jesús (2014): «Los trabajos temporales de Colaboración Social», disponible en http://www.citapreviainem.es/los-trabajos-temporales-de-colaboracion-social/.

Perona Mata, Carmen (2011): «Modificaciones de la Ley 27/2011, de 1 de agosto, sobre actualización, adecuación y modernización del sistema de Seguridad Social», Federación de Enseñanza de CC.OO. Gabinete Técnico-Jurídico, www.fe.ccoo.es

Prieto Rodríguez, Carlos; Caprile, María; Potrony, Jordi y Arnal, María (2009): «La calidad del empleo en España: una aproximación teórica y empírica», Ministerio de Trabajo e Inmigración, 2009, ISBN 978-84-8417-348-9.

Prieto Rodríguez, Carlos (2007): «Del estudio del empleo como norma social al de la sociedad como orden social. Carlos Prieto Rodríguez», Papeles del CEIC (Centro de Estudios para la Identidad Colectiva), ISSN-e 1695-6494, Volumen 2007/1, N.o 1. 
Ramírez, Begoña P. (2013): «4500 parados trabajan en España con el modelo de colaboración social que promueve la Comunidad de Madrid», disponible en http://www. infolibre.es/noticias/economia/2013/05/29/4_500_parados_trabajan_espana_con_ modelo_colaboracion_social_que_promueve_madrid_4217_1011.html

Rojo Torrecilla, Eduardo (2013): «Nuevamente sobre los trabajos temporales de colaboración social. A propósito de la polémica en la Comunidad de Madrid por la Orden 2445/2013 de 16 de mayo». Eduardo Rojo, disponible en http://www. eduardorojotorrecilla.es/2013/06/nuevamente-sobre-los-trabajos.html.

Sanz de Miguel, Pablo (2013): «El discurso de la activación dentro de la Estrategia Europea de Empleo. Análisis de los marcos interpretativos», Fundación CIREM, Intersticios, Revista Sociológica de Pensamiento Crítico, ISSN 1887-3898, Vol. 7 (1) 2013, pp. 241-248.

«Trabajos de colaboración social. Cuando estos solo redundan en beneficio de la Administración» (2013), CEFGestión: Revista de actualización empresarial, ISSN 11394986, N.o 178, 2013, pp. 75-80.

Torrents Margalef, Jorge (2006): «La activación actual de los desempleados en España ante las tendencias selectiva en Europa", Relaciones Laborales, revista crítica de teoría y práctica, Número 12, año XXII, 23 de junio de 2006.

Torrents Margalef, Jorge (2006): «El marco jurídico de la activación de los demandantes de desempleo», Cuadernos de Relaciones Laborales, 2006, 24, núm. 2, 21-36, ISSN: 1131-8635. 


\section{Anexo I}

\section{Relación entre los trabajos de colaboración social y el subsidio por desempleo} para mayores de 55 años

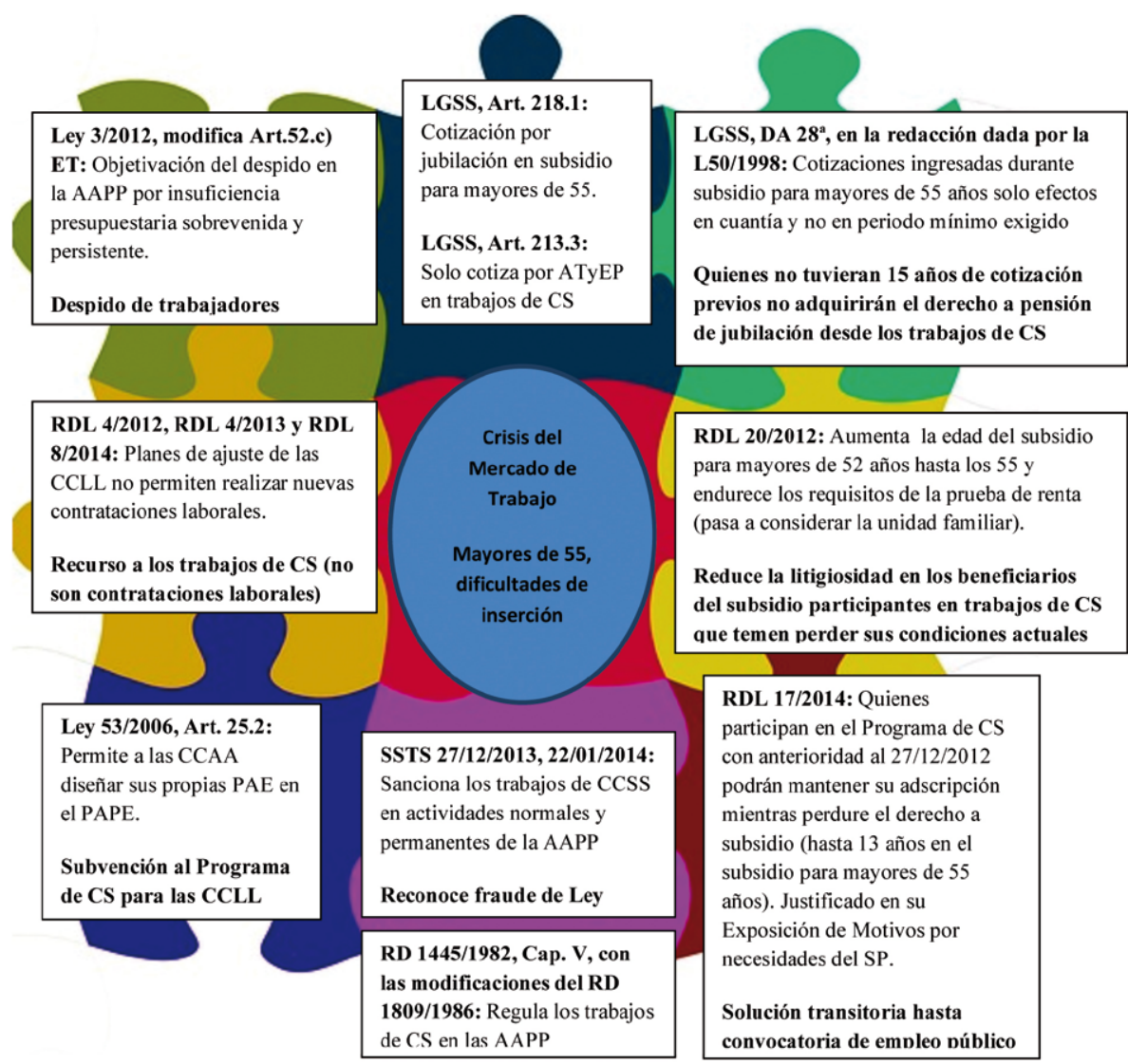

Fuente: elaboración propia. 